\title{
The energy demand estimation for Turkey using differential evolution algorithm
}

\author{
MEHMET BESKIRLI*(D, HUSEYIN HAKLI and HALIFE KODAZ \\ Department of Computer Engineering, Selcuk University, 42075 Konya, Turkey \\ e-mail: mehmetbes@ selcuk.edu.tr
}

MS received 5 December 2016; revised 27 January 2017; accepted 20 February 2017; published online 21 September 2017

\begin{abstract}
The energy demand estimation commands great importance for both developing and developed countries in terms of the economy and country resources. In this study, the differential evolution algorithm (DE) was used to forecast the long-term energy demand in Turkey. In addition to being employed for solving regular optimization problems, DE is also a global, meta-heuristic algorithm that enables fast, reliable and operative stochastic searches based on population. Considering the correlation between the increase in certain economic indicators in Turkey and the increase of energy consumption, two equations were used-one applying the linear form and the other the quadratic form. Turkey's long-term energy demand from 2012 to 2031 was estimated through the DE method in three different scenarios and in terms of the gross domestic product, import, export and population. To prove the success of the DE method in addressing the energy demand problem, the DE method was compared to other methods found in the literature. Results showed that the proposed DE method was more successful than the other methods. Furthermore, the future projections of energy demand obtained using the proposed method were compared to the indicators of energy demand estimated and observed by the Ministry of Energy and Natural Resources.
\end{abstract}

Keywords. Differential evolution algorithm; optimization; energy demand; estimation; Turkey.

\section{Introduction}

The harnessing of energy has been a practice marking every stage of human history and has continued to be an indispensable factor in the economic and social development of countries, from past to present. Being one of the most important requirements for countries, energy functions as an indicator of a country's level of development. Advancements made over time in social, economic and industrial areas have led to an increase in the energy needs of countries. Energy's increasing importance in sustaining human life is unquestionable, and despite the recent occurrences of nuclear power station accidents and financial crises, energy demand continues to rise [1]. Accordingly, it is rather imperative that plans be devised for energy demand, supply, transmission, distribution and pricing in order to secure a healthy development of the energy sector [2]. Arguably, the most important planning study is the determination of future demand, which is made by making comparisons of the current increasing demand for energy. Due to energy's non-storability and the high costs associated with energy generation, it is vital that an operable balance exists between the generation and the consumption of energy [3]. This need to maintain a balance

*For correspondence makes it even more important that the energy demand estimation be accurately determined. The success of planning studies is, in effect, based on the accuracy of the estimations. It was not until the late 1990s that energy estimation studies gained prominence in Turkey, although they had been conducted for a long time in other countries. In the late 1970s, the State Planning Organization (SPO), the Turkish Statistical Institute (TSI) and the Ministry of Energy and Natural Resources (MENR) began applying mathematical models to determine energy demand [4].

Tiris [5] has stated that global energy demand would increase by approximately $1.7 \%$ per year from 2002 to 2030. According to data from 2012, Turkey's total primary energy demand was 121 MTEP. This demand consists of $31 \%$ coal, $31 \%$ natural gas, $25 \%$ petrol, $4 \%$ hydraulics, $3 \%$ wood-waste material, animal and plant waste, geothermal energy, wind and sun, and 3\% other resources [6]. Turkey is capable of generating $30 \%$ of the energy it requires, while imported resources supply the rest [7].

Turkey's primary energy consumption resources largely consist of lignite coal, hard coal, hydroelectric power, petrol, natural gas, geothermal energy, solar energy, wind power and animal and plant waste [8]. However, because Turkey meets most of its energy demand from fossil fuels, such as oil and natural gas, it has had to rely on external resources. Since 2002, the substantial growth seen in the 
Turkish economy has resulted in an increase in energy consumption. With this increased rate of consumption, it is important that Turkey, which satisfies $70 \%$ of its energy need through import, estimates the magnitude of its longterm energy demand correctly in order to avert any potential problems from arising in development and industrialization, budget planning, access to energy resources and investments [7]. If the projected energy demand is less than the actual energy demand, this could lead to an energy crisis, and conversely, if the estimated energy demand is greater than the actual energy demand, this could lead to a decrease in resources and damage to the economy [9]. Naturally, reasonable degrees of deviations in demand estimations are to be expected [10]. However, in this study, substantial deviations, those exceeding the rate of $30 \%$, were observed between the estimations of primary energy demand made in the past and the actual demands. Table 1 shows the years in which these substantial deviations in the demand estimations took place. In effect, these deviations resulted in a higher number of natural gas import agreements than what Turkey needed. Turkey's foreigndependency on energy has increased because of these agreements, and high capacity restrictions have been placed on coal mining operations as well on the stations operating on the basis of coal reserves [6]. After examining the deviation ratio of the estimation studies on the primary energy demand to the actual results, it is clear that methods that permit more accurate estimation of energy demand are required.

To estimate Turkey's primary energy demand, several studies were conducted using different techniques, including statistical techniques [11-16], artificial intelligence techniques [17-19] and heuristic techniques [8, 9, 20-28].

Today, many of the problems related to engineering applications have been adequately addressed using heuristic methods. Population-based heuristic algorithms in particular can quite rapidly yield results through their multipoint procedures. In this study, a population-based differential evolution algorithm (DE or DEA) was proposed to properly estimate the necessary primary energy supply-demand magnitude. DE is an efficient and effective global optimizer, involving a simple, yet reliable population-based stochastic search technique. DE has many advantages: it is fast compared with other algorithms, it can be applied on

Table 1. Turkey's primary energy demand estimation, actual demand and deviations [6].

\begin{tabular}{lccc}
\hline Years & $\begin{array}{c}\text { Estimation } \\
\text { (MTOE) }\end{array}$ & $\begin{array}{c}\text { Actual } \\
\text { (MTOE) }\end{array}$ & $\begin{array}{c}\text { Deviation ratio } \\
(\%)\end{array}$ \\
\hline 2000 & 91 & 81 & 11 \\
2005 & 125 & 91 & 27 \\
2010 & 175 & 109 & 38 \\
2011 & 184 & 115 & 38 \\
2012 & 194 & 121 & 38 \\
\hline
\end{tabular}

large-sized complex problems and it requires fewer number of control parameters. It does however have certain disadvantages as well, such as unsteady convergences and imperfect local optimum determination [29, 30]. DE has been applied in many areas, such as scheduling [31], network modelling [32], image thresholding [33], fan knife designing [34], function optimization [35, 36], feature selection [37] and yield curve estimation [38].

In this study, Gross Domestic Product (GDP), population and import and export data were used as the indicator parameters for the energy demand estimation in the proposed DE method, which was used for both linear and quadratic energy estimation models. On comparing the success of the proposed method's estimation to that of other studies in the literature, it was determined that the DE method enabled the most successful estimation. The primary magnitude of Turkey's energy supply-demand estimation was achieved using the obtained values in new, proposed scenarios. The estimations, which were found to be very close to the observed magnitude of energy demand, were also compared to the primary energy demand estimations made by the MENR.

In section 2 of this paper, the DE is explained. In section 3, the results of the experimental studies are given, and in section 4 , the conclusion and recommendations for future studies are presented.

\section{DE}

The DE is a reliable, population-based, universal algorithm that is commonly used in optimization problems [39-41]. These kinds of algorithms also qualify as numerical optimization algorithms for general purposes. DE, which was developed by Storn and Price [42] in 1995, yields particularly sound results in constant data problems. A well-developed, effective mutation process is used in the DE [43]. This mutation process, which is based on the targeted individual pair differences, is determined by the targeted individual's own distributions. Furthermore, to produce one test individual from one parental individual, mutation and crossover are used together [44]. During the iterations, better solutions to the problem can be searched, with the help of the operators [42, 45]. Compared with other heuristic techniques, one superior feature of DE is that it can be easily codified [46]. Figure 1 presents a DE flowchart [47].

The number of variables involved in the problem and the number of dimensions for each individual are, respectively, expressed as $i$ and $D(1,2,3, \ldots, i)$; the number of individuals determined by the user is expressed as $N P$ and $N P \geq 4(1,2,3, \ldots, i)$. The initial population $P_{0}$, which consists of $N P$ times $D$ dimensioned individual at the beginning, is indicated in Eq. (1); Here, $G$ is the generation number with $i$ individuals and $j$ parameters; $x_{j}^{(l)}$ is the lowest value of the variables and $x_{j}^{(u)}$ is the highest value $[44,48]$. 


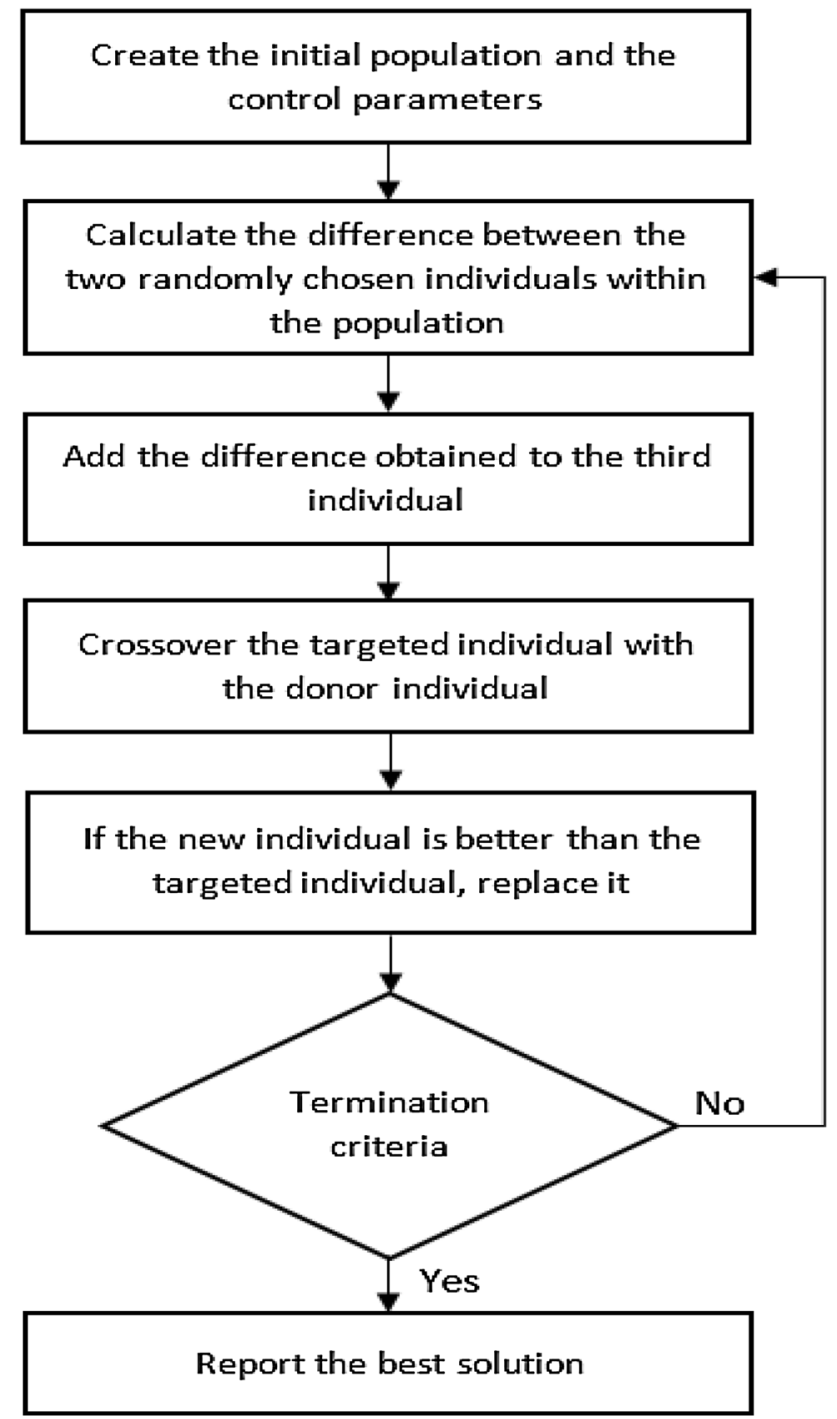

Figure 1. Flowchart of DE algorithm.

$$
x_{j, i, G=0}=x_{j}^{(l)}+\operatorname{rand}_{j}[0,1] \cdot\left(x_{j}^{(u)}-x_{j}^{(l)}\right) .
$$

Mutation refers to the making of a randomly chosen number of changes in certain parameters of the existing individuals. In the DE, three different individuals are chosen, apart from the individual on whom the mutation will be applied. The difference between the first and the second individual is calculated, with the result being multiplied by the $F$ (scaling factor) parameter. The $F$ parameter's value generally ranges between 0 and 2 . The obtained weighted difference individual is added to the third individual. In the end, determination of the donor individual that will be used in the mutation-resulted crossover is achieved:

$$
n_{m, G+1}=x_{r_{3}, G}+F \cdot\left(x_{r_{1}, G}-x_{r_{2}, G}\right) .
$$

In Eq. (2), $n_{m, G+1}$ indicates the mutation and the donor individual that had been subjected to the crossover, and $r_{1}, r_{2}, r_{3}$ indicate the randomly selected individuals that will be used in the production of the new individual $\left(r_{1}, r_{2}, r_{3} \in[1,2,3, \ldots, N P], \quad r_{1} \neq r_{2} \neq r_{3} \neq i\right)[14]$.

When doing the crossover, the donor individual derived from the mutation $n_{m, G+1}$ and the new generation candidate individual $\left(u_{i, G+1}\right)$ are produced using the targeted individual $x_{i, G}$. Each parameter is chosen from donor individual at $\mathrm{CR}$ (crossover ratio) probability, and from the existing individual at $(1-C R)$ probability. In the DE, CR probability is used instead of equal probability. If the random number produced between 0 and 1 is lower than CR, it is chosen from the donor individual, while if it is higher than this ratio, it is chosen from the existing individual. The condition $j=j_{\text {rand }}$ in Eq. (3) is placed to guarantee that at least one parameter is taken from the newly produced individual. The parameter at the randomly chosen point $j_{\text {rand }}$ is selected from $n_{j, i, G+1}$, irrespective of CR.

$x_{j, u, G+1}=\left\{\begin{array}{ll}n_{j, m, G+1} & \text { if } \operatorname{rand}[0,1] \leq C R \text { or } j=j_{\text {rand }} \\ x_{j, i, G} & \text { otherwise }\end{array}\right.$.

A new individual (candidate individual) is generated via mutation and crossover operators using three different individuals, along with the targeted individual. The criteria for determining the individual that will pass to the next generation are the values of the individual's fitness. If the fitness value of the candidate individual is better than that of the targeted individual, the candidate individual is transferred to the next generation in place of the targeted individual. If the fitness value of the targeted individual is better, then the targeted individual is kept in the memory. This process is demonstrated in Eq. (4):

$$
x_{i, G+1}=\left\{\begin{array}{ll}
x_{u, G+1} & \text { if } f\left(x_{u, G+1}\right) \leq f\left(x_{i, G+1}\right) \\
x_{i, G} & \text { otherwise }
\end{array}\right\} .
$$

The steps that are stated above (between Eqs. (2) and (4)) are repeated until a termination criterion is achieved. When the algorithm is completed, the solution that has the best fitness value is reported. For a more detailed explanation, see $[41,42]$.

\section{Applying the proposed method to the energy demand estimation problem}

Energy demand models were developed using the four economy-based criteria that were indicated in the literature: GDP, population, import and export. As these factors are believed to have the biggest impact on determining a country's need for energy, the data related to these criteria were used with the DE to develop energy demand models. Table 2 shows Turkey's GDP, population, import, export, energy production, electricity production and electricity consumption data from 1979 to 2011 , as well as its energy demand value. These data were obtained from the TSI, the 
Table 2. Turkey's energy demand, GDP, population, import, export, energy production, electricity production and electricity consumption data.

\begin{tabular}{|c|c|c|c|c|c|c|c|c|}
\hline \multirow[b]{2}{*}{ Year } & \multirow[b]{2}{*}{$\begin{array}{c}\text { Energy demand } \\
\text { (MTOE) }\end{array}$} & \multicolumn{7}{|c|}{ Name and number of variables } \\
\hline & & $\begin{array}{c}1 \\
\text { GDP } \\
\left(\$ 10^{9}\right)\end{array}$ & $\begin{array}{c}2 \\
\text { Population } \\
\left(10^{6}\right)\end{array}$ & $\begin{array}{c}3 \\
\text { Import } \\
\left(\$ 10^{9}\right)\end{array}$ & $\begin{array}{c}4 \\
\text { Export } \\
\left(\$ 10^{9}\right)\end{array}$ & $\begin{array}{c}5 \\
\text { Energy } \\
\text { production }\left(10^{9}\right)\end{array}$ & $\begin{array}{c}6 \\
\text { Electricity } \\
\text { production }\left(10^{9}\right)\end{array}$ & $\begin{array}{c}7 \\
\text { Electricity } \\
\text { consumption }\left(10^{9}\right)\end{array}$ \\
\hline 1979 & 30.71 & 82 & 45.53 & 5.07 & 2.26 & 17.32 & 22.52 & 19.63 \\
\hline 1980 & 31.97 & 68 & 44.44 & 7.91 & 2.91 & 17.36 & 23.28 & 20.40 \\
\hline 1981 & 32.05 & 72 & 45.54 & 8.93 & 4.70 & 18.30 & 24.67 & 22.03 \\
\hline 1982 & 34.39 & 64 & 46.69 & 8.84 & 5.75 & 19.19 & 26.55 & 23.59 \\
\hline 1983 & 35.70 & 60 & 47.86 & 9.24 & 5.73 & 19.31 & 27.35 & 24.47 \\
\hline 1984 & 37.43 & 59 & 49.07 & 10.76 & 7.13 & 20.32 & 30.61 & 27.64 \\
\hline 1985 & 39.40 & 67 & 50.31 & 11.34 & 7.95 & 21.94 & 34.22 & 29.71 \\
\hline 1986 & 42.47 & 75 & 51.43 & 11.10 & 7.46 & 23.54 & 39.70 & 32.21 \\
\hline 1987 & 46.88 & 86 & 52.56 & 14.16 & 10.19 & 25.08 & 44.35 & 36.70 \\
\hline 1988 & 47.91 & 90 & 53.72 & 14.34 & 11.66 & 24.61 & 48.05 & 39.72 \\
\hline 1989 & 50.71 & 108 & 54.89 & 15.79 & 11.62 & 25.75 & 52.04 & 43.12 \\
\hline 1990 & 52.98 & 151 & 56.10 & 22.30 & 12.96 & 25.48 & 57.54 & 46.82 \\
\hline 1991 & 54.27 & 150 & 57.19 & 21.05 & 13.59 & 25.50 & 60.25 & 49.28 \\
\hline 1992 & 56.68 & 158 & 58.25 & 22.87 & 14.72 & 26.78 & 67.34 & 53.99 \\
\hline 1993 & 60.26 & 179 & 59.32 & 29.43 & 15.35 & 26.42 & 73.81 & 59.24 \\
\hline 1994 & 59.12 & 132 & 60.42 & 23.27 & 18.11 & 26.49 & 78.32 & 61.40 \\
\hline 1995 & 63.68 & 170 & 61.53 & 35.71 & 21.64 & 26.70 & 86.25 & 67.39 \\
\hline 1996 & 69.86 & 184 & 62.67 & 43.63 & 23.22 & 27.37 & 94.86 & 74.16 \\
\hline 1997 & 73.78 & 192 & 63.82 & 48.56 & 26.26 & 28.19 & 103.30 & 81.89 \\
\hline 1998 & 74.71 & 207 & 65.00 & 45.92 & 26.97 & 29.27 & 111.02 & 87.71 \\
\hline 1999 & 76.77 & 187 & 66.43 & 40.67 & 26.59 & 27.59 & 116.44 & 91.20 \\
\hline 2000 & 80.50 & 200 & 67.42 & 54.50 & 27.78 & 25.99 & 124.92 & 98.30 \\
\hline 2001 & 75.40 & 146 & 68.37 & 41.40 & 31.33 & 24.55 & 122.73 & 97.07 \\
\hline 2002 & 78.33 & 181 & 69.30 & 51.55 & 36.06 & 24.25 & 129.40 & 102.95 \\
\hline 2003 & 83.84 & 239 & 70.23 & 69.34 & 47.25 & 23.73 & 140.58 & 111.77 \\
\hline 2004 & 87.82 & 299 & 71.15 & 97.54 & 63.17 & 24.27 & 150.70 & 121.14 \\
\hline 2005 & 91.58 & 361 & 72.97 & 116.77 & 73.48 & 24.47 & 161.96 & 130.26 \\
\hline 2006 & 99.59 & 483 & 72.97 & 139.58 & 85.54 & 26.50 & 176.30 & 143.07 \\
\hline 2007 & 107.63 & 531 & 70.59 & 170.06 & 107.27 & 27.37 & 191.56 & 155.14 \\
\hline 2008 & 106.27 & 648 & 71.13 & 201.96 & 132.03 & 29.12 & 198.42 & 161.95 \\
\hline 2009 & 106.14 & 730 & 73.23 & 140.93 & 102.14 & 30.27 & 194.81 & 156.89 \\
\hline 2010 & 109.27 & 615 & 74.47 & 185.54 & 113.88 & 32.43 & 211.21 & 172.05 \\
\hline 2011 & 114.48 & 731 & 74.72 & 240.84 & 134.91 & 32.23 & 229.40 & 186.10 \\
\hline
\end{tabular}

MENR, the Energy Reports and previous studies $[6,7,49-51]$.

Table 2 indicates that Turkey is in the process of continuous development and that its economic values have increased over the years. Furthermore, it can be concluded from the table that there is a correlation between the increase in the economic values and the increase in energy consumption. Assuming this correlation, the energy demand estimation is modelled in two different ways: linear (5) and quadratic (6).

The equation governing the linear form for four variables can be written as follows [8, 9]:

$$
E_{\text {linear }}=w_{1}+w_{2} X_{1}+w_{3} X_{2}+w_{4} X_{3}+w_{5} X_{4} .
$$

The equation governing the quadratic form for four variables can be written as follows $[8,9]$ :

$$
\begin{aligned}
E_{\text {quadratic }}= & w_{1}+w_{2} X_{1}+w_{3} X_{2}+w_{4} X_{3}+w_{5} X_{4}+w_{6} X_{1} X_{2} \\
& +w_{7} X_{1} X_{3}+w_{8} X_{1} X_{4}+w_{9} X_{2} X_{3}+w_{10} X_{2} X_{4} \\
& +w_{11} X_{3} X_{4}+w_{12} X_{1}^{2}+w_{13} X_{2}^{2}+w_{14} X_{3}^{2}+w_{15} X_{4}^{2} .
\end{aligned}
$$

The main purpose behind the energy demand estimation is to find the most appropriate values for the data. In Eqs. (5) and (6), the $X_{1}, X_{2}, X_{3}$ and $X_{4}$ values indicate actual GDP, population, import and export values. The weight values $\left(w_{i}\right)$ that enable the most suitable energy demand estimation for the given years are calculated according to these said values. The objective function that is used is shown in the following equation:

$$
\min f(v)=\sum_{r=1}^{R}\left(E_{r}^{\text {observed }}-E_{r}^{\text {predicted }}\right)^{2}
$$


where the values of $E_{r}^{\text {observed }}$ and $E_{r}^{\text {predicted }}$ indicate the real and the estimated values, respectively, while $r$ indicates the number of observations.

\subsection{Comparison of DE and other models in the literature}

To observe whether or not the DE method was successful in resolving the estimation of energy demand problem, it was compared to other models used in the literature. In previous studies, different heuristic algorithms, including ACO by Toksari, PSO by Unler and HAPE by Kiran, were applied to the energy demand estimation problem. In order to evaluate and fairly compare the proposed model to the algorithms in the literature, the 1979-2005 data given in table 2 were used in the DE, just as in the other algorithms. For the DE algorithm, the scaling factor $F$ and CR were determined to be 0.5 and 0.9 , respectively, while the population size was 100 and the maximum iteration number was 5000. Therefore, the maximum number of function evaluations was set to be $5 \times 10^{5}$. All the codes were executed with MATLAB 2014 (8.3).

DE was executed 10 times for the two models, with selected variables $1,2,3$ and 4 . The best results obtained were taken into consideration. Weights (coefficients) for the linear form were as follows:

$$
\begin{aligned}
E_{\text {linear }}= & 0.00380 X_{1}+1.91227 X_{2}+0.37354 X_{3} \\
& -0.48351 X_{4}-55.89907, \\
f(v)_{\text {linear }}= & 41.71200 .
\end{aligned}
$$

Coefficients for the quadratic form of the proposed model were as follows:

$$
\begin{aligned}
E_{\text {quadratic }}= & -0.48335 X_{1}+4.76744 X_{2}+1.09908 X_{3} \\
& -2.92119 X_{4}+0.01883 X_{1} * X_{2} \\
& +0.02308 X_{1} * X_{3}-0.02555 X_{1} * X_{4} \\
& -0.06267 X_{2} * X_{3}+0.10201 X_{2} * X_{4} \\
& +0.09233 X_{3} * X_{4}-0.00274 X_{1}^{2} \\
& -0.04692 X_{2}^{2}-0.03898 X_{3}^{2}-0.06576 X_{4}^{2} \\
& -97.14579 \\
f(v)_{\text {quadratic }}= & 17.65225 .
\end{aligned}
$$

For the linear and quadratic forms, coefficients and error values of DE, HAPE, ACO and PSO algorithms are given in tables 3 and 4. The coefficients and deviation ratios of the other algorithms, besides those of the DE, were taken from the study conducted by Kiran et al [8]. Table 3 clearly shows that the coefficients and deviation ratios for the linear form of the DE and HAPE methods are very similar, while the other two methods have higher deviation values. Table 4 reveals that the quadratic form is more successful,
Table 3. Comparisons of coefficients and relative errors in linear form.

\begin{tabular}{lrrrr}
\hline Coefficients & \multicolumn{1}{c}{ DE } & \multicolumn{1}{c}{ HAPE } & \multicolumn{1}{c}{ ACO } & \multicolumn{1}{c}{ PSO } \\
\hline$w 1$ & -55.8991 & -55.9091 & -51.3046 & -55.9022 \\
$w 2$ & 0.0038 & 0.0038 & 0.0124 & 0.0021 \\
$w 3$ & 1.9123 & 1.9126 & 1.8102 & 1.9126 \\
$w 4$ & 0.3735 & 0.3734 & 0.3524 & 0.3431 \\
$w 5$ & -0.4835 & -0.4833 & -0.4439 & -0.4240 \\
R. error & 41.7120 & 41.7029 & 45.7239 & 42.6139 \\
\hline
\end{tabular}

Table 4. Comparisons of coefficients and relative errors in quadratic form.

\begin{tabular}{lrrrr}
\hline Coefficients & \multicolumn{1}{c}{ DE } & \multicolumn{1}{c}{ HAPE } & \multicolumn{1}{c}{ ACO } & \multicolumn{1}{c}{ PSO } \\
\hline$w 1$ & -97.14579 & -43.3096 & -96.4418 & -96.4408 \\
$w 2$ & -0.48335 & 0.1039 & -0.4820 & -0.4820 \\
$w 3$ & 4.76744 & 1.8110 & 4.7370 & 4.7370 \\
$w 4$ & 1.09908 & -1.4778 & 1.0937 & 1.0937 \\
$w 5$ & -2.92119 & 1.1174 & -2.8935 & -2.9350 \\
$w 6$ & 0.01883 & 0.0025 & 0.0188 & 0.0188 \\
$w 7$ & 0.02308 & 0.0112 & 0.0230 & 0.0230 \\
$w 8$ & -0.02555 & -0.0074 & -0.0255 & -0.0255 \\
$w 9$ & -0.06267 & 0.0121 & -0.0625 & -0.0625 \\
$w 10$ & 0.10201 & -0.0030 & 0.1014 & 0.1014 \\
$w 11$ & 0.09233 & 0.0158 & 0.0915 & 0.0915 \\
$w 12$ & -0.00274 & -0.0014 & -0.0027 & -0.0027 \\
$w 13$ & -0.04692 & -0.0070 & -0.0466 & -0.0466 \\
$w 14$ & -0.03898 & -0.0170 & -0.0389 & -0.0387 \\
$w 15$ & -0.06576 & -0.0104 & -0.0651 & -0.0651 \\
R. error & 17.6523 & 20.5393 & 27.9470 & 27.6640 \\
\hline
\end{tabular}

given that it yields the lowest deviation values when applied on the methods.

The deviation value that was found for both the quadratic form and the linear form using the DE method demonstrates that compared with the other methods, the DE method yielded energy demand estimation values that were nearer to the values observed between 1979 and 2005. The data from tables 3 and 4 illustrate that the DE method is stronger and more successful in addressing the energy demand estimation problem than the other methods found in the literature.

Table 5 presents the observed energy demand values and the energy demand estimated through the DE method between 1996 and 2005 for linear and quadratic forms. Table 5 also shows the deviation value and relative error between the estimated and the observed values. Although the highest deviation value was $-3.37 \%$ for the linear form and $2.27 \%$ for the quadratic form, these deviation ratios were nonetheless considered to be quite acceptable. It can be put forward that in cases of fluctuations of economic indicators, the quadratic model would provide better solutions. 
Table 5. Energy demand estimation of the proposed models between 1996 and 2005 .

\begin{tabular}{|c|c|c|c|c|c|c|c|}
\hline \multirow[b]{2}{*}{ Years } & \multirow[b]{2}{*}{$\begin{array}{l}\text { Observed energy demand } \\
\text { (MTOE) }\end{array}$} & \multicolumn{2}{|c|}{$\begin{array}{c}\text { Estimated energy demand } \\
\text { (MTOE) }\end{array}$} & \multicolumn{2}{|c|}{ Magnitude of errors } & \multicolumn{2}{|c|}{ Relative errors (\%) } \\
\hline & & $\begin{array}{l}\text { Linear } \\
\text { (DEL) }\end{array}$ & $\begin{array}{l}\text { Quadratic } \\
\text { (DEQ) }\end{array}$ & $\begin{array}{l}\text { Linear } \\
(\mathrm{DEL})\end{array}$ & $\begin{array}{l}\text { Quadratic } \\
\text { (DEQ) }\end{array}$ & $\begin{array}{l}\text { Linear } \\
\text { (DEL) }\end{array}$ & $\begin{array}{l}\text { Quadratic } \\
\text { (DEQ) }\end{array}$ \\
\hline 1996 & 69.86 & 69.71 & 69.78 & -0.15 & -0.08 & -0.21 & -0.12 \\
\hline 1997 & 73.78 & 72.32 & 72.93 & -1.46 & -0.85 & -1.99 & -1.16 \\
\hline 1998 & 74.71 & 73.30 & 74.63 & -1.41 & -0.08 & -1.89 & -0.10 \\
\hline 1999 & 76.77 & 74.18 & 75.25 & -2.59 & -1.52 & -3.37 & -1.99 \\
\hline 2000 & 80.50 & 80.71 & 80.79 & 0.21 & 0.29 & 0.27 & 0.36 \\
\hline 2001 & 75.40 & 75.71 & 74.47 & 0.31 & -0.93 & 0.42 & -1.23 \\
\hline 2002 & 78.33 & 79.13 & 80.11 & 0.80 & 1.78 & 1.02 & 2.27 \\
\hline 2003 & 83.84 & 82.37 & 83.61 & -1.47 & -0.23 & -1.76 & -0.27 \\
\hline 2004 & 87.82 & 87.19 & 87.38 & -0.63 & -0.44 & -0.72 & -0.50 \\
\hline 2005 & 91.58 & 93.10 & 91.85 & 1.52 & 0.27 & 1.66 & 0.30 \\
\hline
\end{tabular}

Table 6. Mean relative errors of DE and variant models between 1996 and 2005.

\begin{tabular}{lccccc}
\hline $\begin{array}{l}\text { Algorithms-linear } \\
\text { form }\end{array}$ & $\begin{array}{c}\text { Mean absolute } \\
\text { relative error }\end{array}$ & $\begin{array}{c}\text { Algorithms-quadratic } \\
\text { form }\end{array}$ & $\begin{array}{c}\text { Mean absolute } \\
\text { relative error }\end{array}$ & $\begin{array}{c}\text { Total absolute } \\
\text { relative error }\end{array}$ & References \\
\hline PSO-LR & 1.43 & PSO-QR & 0.83 & 2.26 & Unler \\
ACO-L & 1.41 & ACO-Q & 1.20 & 2.61 & Toksari \\
HAPEL & 1.33 & HAPEQ & 1.03 & 2.36 & Kiran \\
DE-L & 1.33 & DE-Q & 0.83 & 2.16 & Proposed method \\
\hline
\end{tabular}

The mean absolute relative error values of the linear and quadratic models between 1996 and 2005 are given in table 6 in order to offer a comparison between the proposed algorithm and the other algorithms that have been presented in the literature as answers to the energy demand estimation problem. In terms of the lowest error rates, the given data show that DE's mean absolute relative error rate is 1.33 using the HAPEL algorithm in the linear form and 0.83 using the PSO algorithm in the quadratic form. It is important here to note that the error rates given in this table are arranged according to the training data from the last 10 years. The error values shown for all the years in tables 3 and 4 clearly demonstrate that DE algorithms are more successful. Table 6 presents the mean absolute relative errors for linear and quadratic forms from the last 10 years and shows that the best values are obtained using the proposed method.

The level of energy demand observed between 1996 and 2005 using DE, ACO, PSO and HAPE algorithms for linear and quadratic forms are shown in figures 2 and 3, respectively. Figure 2 indicates that HAPE and the proposed method made similar estimations, and that the results obtained through these methods were closer to the observed energy demand than the results obtained through the other algorithms. ACO algorithm seemed to provide poorer estimations, and they generally stayed below the level of observed energy demand.

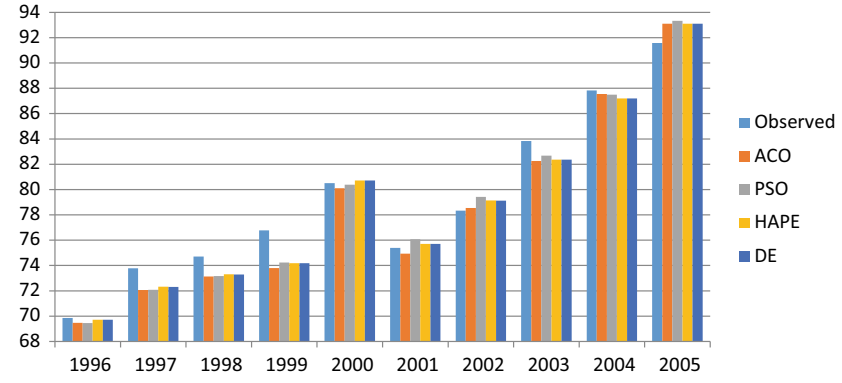

Figure 2. Comparisons of energy demand according to algorithms in linear form between 1996 and 2005.

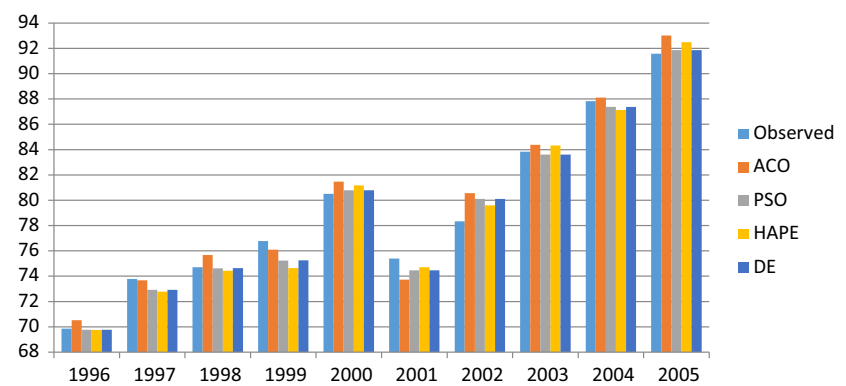

Figure 3. Comparisons of energy demand according to algorithms in quadratic form between 1996 and 2005. 
Figure 3 indicates that the PSO and DE methods in the quadratic form provided values closer to the observed energy demand compared with those from the other studies. Considering the level of errors in tables 3 and 4, the mean absolute relative error in table 6 and the estimations in figures 2 and 3, DE appears to be more successful in the energy demand estimation problem than the other methods presented in the literature.

\subsection{Estimation of energy demand problem through different variables}

Different variables, in addition to GDP, population, and import and export variables, for the energy demand estimation problem can also be used [27, 28]. In this study, the energy demand estimation was determined using energy production, electricity production and electricity consumption variables in order to decrease the error ratio. Data on these variables between the years 1979 and 2011 are shown in table 2 . The basic factors largely responsible for affecting energy demand estimation-GDP, population, import and export values-were directly applied to equations in different combinations [52]. Equation (6) was updated with the variables that are shown in table 2 (except for the default variables 1, 2, 3 and 4) according to the number of variables used, by determining three different combinations.

Using the quadratic form, three different combinations were run 10 times for data spanning the years between 1979 and 2011. The best error values obtained after 10 runsbased on best fitness values given in Eq. (7) — are shown in table 7 .

The most successful energy demand estimation for the years between 1979 and 2011 was achieved using variables 1, 2, 3 and 4. A slight increase was observed in the error value when an energy production variable was added to these variables. It can be observed from table 7 that the error value increases considerably when variables 1, 2, 3, 4, 6 and 7 are used. Slight increases in error value have a greater reflection on the fitness value due to the squaring of the error value found for each year in the fitness function. This combination was used for future projection since the minimum error value was obtained using variables 1, 2, 3 and 4.

Table 7. Best fitness values obtained for different variable values.

\begin{tabular}{lc}
\hline Best fitness & Selected variables \\
\hline 42.61 & $1,2,3,4$ \\
46.94 & $1,2,3,4,5$ \\
78.58 & $1,2,3,4,7$ \\
9936.81 & $1,2,3,4,6,7$ \\
\hline
\end{tabular}

\subsection{Future projections of energy demand} between 2012 and 2031 through the DE method

After proving the success of the proposed method compared with the other studies in the literature, estimations for Turkey's energy demand between 2012 and 2031 were made by determining new coefficients for linear and quadratic forms using the updated data for the years between 1979 and 2011. The given parameter values in section 3.1 were taken exactly as they were, the only difference being that the data range was updated for the years between 1979 and 2011 in order to ensure better estimations using a higher quantity of updated data.

The DE method was executed 10 times for linear and quadratic forms with selected variables 1, 2, 3 and 4, using data for the years between 1979 and 2011 . The weight values and error rates of the best solutions found are given in Eqs. (10) and (11), respectively. These rates were as follows:

$$
\begin{aligned}
E_{\text {linear }}= & 0.02389 X_{1}+1.75763 X_{2}+0.09997 X_{3} \\
& -0.03635 X_{4}-50.13452 \\
f(v)_{\text {linear }}= & 152.57090 .
\end{aligned}
$$

Coefficients for the quadratic form of the proposed model were as follows:

$$
\begin{aligned}
E_{\text {quadratic }}= & 0.31851 X_{1}-3.71922 X_{2}-0.26750 X_{3} \\
& +2.84590 X_{4}-0.00658 X_{1} * X_{2} \\
& -0.00362 X_{1} * X_{3}+0.00677 X_{1} * X_{4} \\
& +0.01385 X_{2} * X_{3}-0.04917 X_{2} * X_{4} \\
& +0.13194 X_{3} * X_{4}+1.45870 X_{1}^{2} \\
& +0.054768 X_{2}^{2}-0.03517 X_{3}^{2}-0.12611 X_{4}^{2} \\
& +81.10198 \\
f(v)_{\text {quadratic }}= & 42.61157
\end{aligned}
$$

To estimate the energy demand of Turkey for the years between 2012 and 2031, three scenarios were created in light of the updated data.

Scenario 1: It is assumed that the average growth rate of GDP is $4 \%$, population growth rate is $0.5 \%$, import growth rate is $2.5 \%$ and export growth rate is $3 \%$ during the period between 2012 and 2031.

Scenario 2: It is assumed that the average growth rate of GDP is $5 \%$, population growth rate is $0.6 \%$, import growth rate is $3.5 \%$ and export growth rate is $3.5 \%$ during the period between 2012 and 2031.

Scenario 3: It is assumed that the average growth rate of GDP is $6 \%$, population growth rate is $0.7 \%$, import growth rate is $4 \%$ and the proportion of import covered by export is $55 \%$ during the period between 2012 and 2031.

Using the coefficients obtained through the DE method and the given scenarios, the energy demand estimation 
Table 8. Future projections of total energy demand in MTOE according to Scenarios 1-3 for the proposed method.

\begin{tabular}{|c|c|c|c|c|c|c|c|}
\hline \multirow[b]{2}{*}{ Year } & \multirow[b]{2}{*}{ Observed energy demand (MTOE) } & \multicolumn{3}{|c|}{ Linear } & \multicolumn{3}{|c|}{ Quadratic } \\
\hline & & Scenario 1 & Scenario 2 & Scenario 3 & Scenario 1 & Scenario 2 & Scenario 3 \\
\hline 2012 & 120.09 & 119.65 & 120.17 & 120.66 & 117.18 & 116.28 & 110.62 \\
\hline 2013 & 120.29 & 121.50 & 122.57 & 123.50 & 119.94 & 118.09 & 112.16 \\
\hline 2014 & 123.94 & 123.39 & 125.05 & 126.44 & 123.02 & 120.20 & 114.09 \\
\hline 2015 & N/A & 125.33 & 127.61 & 129.50 & 126.46 & 122.66 & 116.49 \\
\hline 2016 & N/A & 127.32 & 130.25 & 132.67 & 130.32 & 125.53 & 119.48 \\
\hline 2017 & N/A & 129.35 & 132.97 & 135.96 & 134.63 & 128.88 & 123.18 \\
\hline 2018 & N/A & 131.44 & 135.78 & 139.38 & 139.46 & 132.79 & 127.73 \\
\hline 2019 & N/A & 133.57 & 138.69 & 142.93 & 144.85 & 137.36 & 133.29 \\
\hline 2020 & N/A & 135.76 & 141.69 & 146.63 & 150.88 & 142.67 & 140.08 \\
\hline 2021 & N/A & 138.00 & 144.79 & 150.48 & 157.62 & 148.86 & 148.30 \\
\hline 2022 & N/A & 140.29 & 147.99 & 154.48 & 165.15 & 156.04 & 158.22 \\
\hline 2023 & N/A & 142.65 & 151.31 & 158.65 & 173.55 & 164.37 & 170.13 \\
\hline 2024 & N/A & 145.06 & 154.74 & 162.99 & 182.91 & 174.00 & 184.37 \\
\hline 2025 & N/A & 147.54 & 158.29 & 167.51 & 193.35 & 185.12 & 201.33 \\
\hline 2026 & N/A & 150.08 & 161.96 & 172.23 & 204.97 & 197.93 & 221.47 \\
\hline 2027 & N/A & 152.69 & 165.76 & 177.15 & 217.90 & 212.67 & 245.28 \\
\hline 2028 & N/A & 155.37 & 169.70 & 182.28 & 232.28 & 229.60 & 273.36 \\
\hline 2029 & N/A & 158.12 & 173.78 & 187.64 & 248.25 & 248.99 & 306.36 \\
\hline 2030 & N/A & 160.94 & 178.00 & 193.24 & 265.99 & 271.18 & 345.06 \\
\hline 2031 & N/A & 163.84 & 182.38 & 199.08 & 285.66 & 296.52 & 390.30 \\
\hline
\end{tabular}

values for linear and quadratic forms for the years between 2012 and 2031 are given in table 8 . Table 8 also shows the observed energy demand values between 2012 and 2014 .

Table 8 shows that for the linear form, the estimations are very close to the observed energy demand value in Scenario 1. In the linear form, estimations in Scenarios 2 and 3 increased more rapidly than in Scenario 1, while in the quadratic form, the closest estimations to the observed energy demand values were obtained in Scenario 1. Scenario 3 begins with lower estimations than in the other scenarios, but it presented much higher estimations after a couple of years. Over the years, the estimations that were obtained using the linear form remained below the values obtained in the quadratic form, as expected. In general, Scenario 1, which gave the closest estimation value to the observed energy demand values for both linear and quadratic forms, can be considered to be more applicable than the other scenarios.

Figures 4, 5 and 6 present graphs detailing the energy demand estimations for the linear and quadratic forms used in the proposed method for Scenarios 1, 2 and 3, respectively, the primary energy demand estimations of Turkey made by MENR and the observed energy demand values. The observed energy demand values were taken from 2012, 2013 and 2014 data. The MENR values of 129, 146, 157, 165 and 185 MTOE represent the energy demand estimation data compiled by the MENR for the years 2015, 2020, 2023, 2025 and 2030, respectively [6].

In figure 4, linear form values for Scenario 1 are higher than the MENR values, whereas the quadratic form values are lower than these values. It is observed in figure 4 that

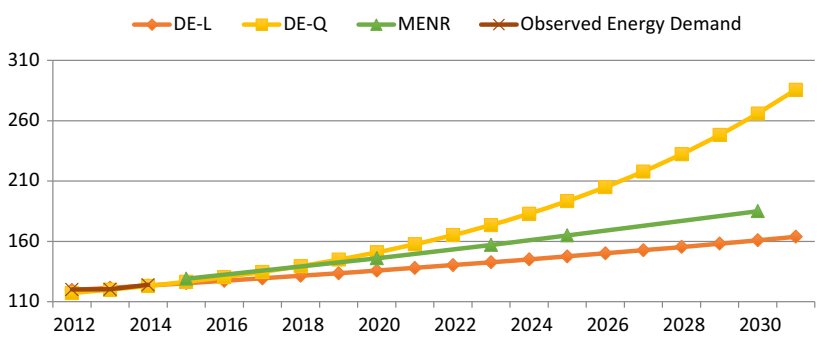

Figure 4. Future projections of total energy demand in MTOE according to Scenario 1.

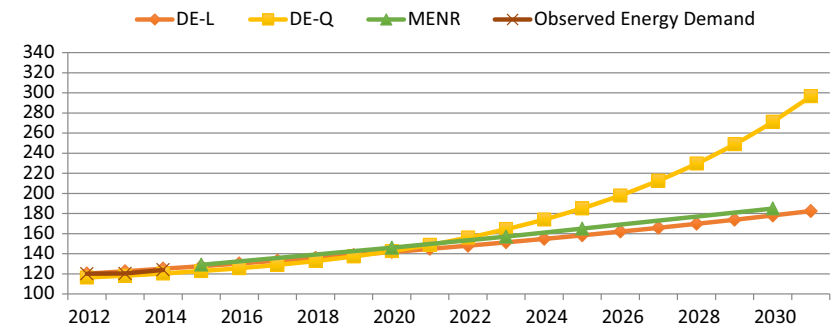

Figure 5. Future projections of total energy demand in MTOE according to Scenario 2.

the estimations made for both linear and quadratic forms are very close to the observed energy demand.

For Scenario 2, figure 5 shows that the values of energy demand estimations in linear form are close to the MENR values; however, these values become much higher than the MENR values, particularly after 2020 . 


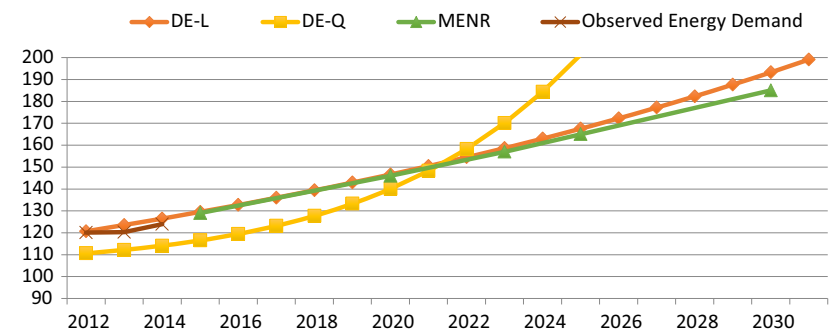

Figure 6. Future projections of total energy demand in MTOE according to Scenario 3.

Figure 6 indicates that the values from the linear form energy demand estimations of Scenario 3 are close to the MENR values. The quadratic form estimation values, on the other hand, were lower than the MENR values up to the year 2023, after which these values became much higher than the MENR values. Thus, it can be concluded that the quadratic form's estimations for Scenario 3 do not comply with the estimations made by MENR.

The energy demand estimations that were made using three different proposed scenarios with the DE method for linear and quadratic forms indicate that Scenario 1 resulted in more accurate estimations. In the case of Scenario 3, it should be noted that a rapid increase took place with the quadratic form and that there were differences seen between the linear models under this scenario.

\subsection{Estimation of energy demand for a different country using the proposed method}

An energy demand estimation for a different country was performed using the proposed method to test the method's success and stability. GDP, population, import and export values of South Korea for the years between 1980 and 2007 were obtained directly from reference [53]. In the study [53], energy demand was estimated by five different models, and these models were compared to each other with respect to their root mean squared errors for the years between 1980 and 2007. The proposed method was run 10 times in the quadratic form using input values specific to South Korea. The best root mean squared error value obtained from the proposed method, as well as the other models, is shown in table 9 .

Table 9. Comparison of models with respect to root mean squared error.

\begin{tabular}{lc}
\hline Model & Root mean squared error \\
\hline Linear regression (LSM) & 8.7210 \\
Exponential (BFGS) & 14.1203 \\
Modified exponential (B\&B) & 6.7018 \\
FF-BP-ANN & 8.5241 \\
Scaled FF-BP-ANN & 5.7803 \\
The proposed method (DE-Q) & 2.3366 \\
\hline
\end{tabular}

The proposed method-by obtaining the most successful result with the minimum error value of 2.3366-performed the energy demand estimation of South Korea for the years between 1980 and 2007. The success and stability of the proposed method was clearly demonstrated by obtaining a successful result using data from a different country.

\section{Conclusion and future works}

This study has attempted to estimate Turkey's long-term primary energy demand using the DE method. The energy demand between 2012 and 2031 was projected using GDP, population, import, export, energy production, electricity production, electricity consumption and 33-year data, developed from the coefficients of linear and quadratic forms, taken between 1979 and 2011. It was determined, based on estimations, that the optimum variables for energy demand estimation were GDP, population, and import and export values. To test the validity of this model, energy demand values from 2012, 2013 and 2014 were used. Furthermore, all the results were compared to the MENR values using three different scenarios. This study obtained the following main results:

- To estimate the energy demand of Turkey, both linear and quadratic forms should be used. Scenarios 1 and 2 yielded values close to the real energy demand values. However, the quadratic form of Scenario 3 yielded a value that was lower than the real estimation value.

- The highest deviation ratio was $-3.37 \%$ for the linear DE, while this ratio was $2.27 \%$ for the quadratic DE. It seems that the quadratic form would provide better solutions in cases of economic fluctuations.

- When estimating Turkey's energy demand using DE forms, MENR findings were also taken into consideration, with the results showing that DE yielded lower values than those found by MENR.

Having developed three separate scenarios to determine the energy demand estimation, it is expected that the findings from this study shall serve to provide insight into and be a model for future studies.

The success of long-term energy demand estimations depends on the scenarios used in studies and on the dataset. In this study, it was observed that the methods used resulted in relative errors. Moreover, when the methods' mean absolute relative errors were evaluated, the lowest level of error for both linear and quadratic forms was obtained using the DE method. Thus, this proposed method has been proven to be a successful tool for energy demand estimation. Lastly, the proposed method was also used to determine the energy demand estimation for South Korea, and the method again proved itself to be stable by performing energy demand estimations with minimum error value compared with other models applied on South Korea. To 
estimate energy demand in future studies, new, hybrid meta-heuristic algorithms can be developed using the dataset from the present study.

\section{Acknowledgements}

This study was supported by the Scientific Research Project of Selcuk University.

\section{References}

[1] Güneş G and Aslan E 2015 Use of renewable energy sources and its effects to sustainable tourism - Turkey example. Doğu Karadeniz Bölgesi Sürdürülebilir Turizm Kongresi. Gümüşhane Üniversitesi Yayınlar1-31, Gümüshane, Turkey, pp. 221-234

[2] Oğurlu H 2011 Matematiksel Modelleme Kullanarak Türkiye'nin Uzun Dönem Elektrik Yük Tahmini. Selçuk Üniversitesi Fen Bilimleri Enstitüsü

[3] Mahmutoğlu M and Öztürk F 2015 Türkiye Elektrik Tüketimi Öngörüsü ve Bu Kapsamda Geliştirilebilecek Politika Önerileri. In: Proceedings of EY International Congress on Economics II (EYC2015), November 5-6, Ankara, Turkey. Ekonomik Yaklasim Association

[4] Erdogdu E 2007 Electricity demand analysis using cointegration and ARIMA modelling: a case study of Turkey. Energy Policy 35: 1129-1146

[5] Tiris M 2005 Global trends for energy. In: Proceedings of the Turkish Workshop on Sustainable Development: Meeting the Challenges, JuØlich

[6] WECTNC 2013 Energy report-2013. Ankara: World Energy Council (in Turkish), ISSN: 1301-63182014

[7] WECTNC 2014 Energy report-2014. Ankara: World Energy Council (in Turkish), ISSN: 1301-63182015

[8] Kıran M S, Özceylan E, Gündüz M and Paksoy T 2012 A novel hybrid approach based on particle swarm optimization and ant colony algorithm to forecast energy demand of Turkey. Energy Convers. Manage. 53: 75-83

[9] Ünler A 2008 Improvement of energy demand forecasts using swarm intelligence: the case of Turkey with projections to 2025. Energy Policy 36: 1937-1944

[10] TMMOB 2014 Türkiye'nin enerji görünümü. MMO2014

[11] Ediger V Ş and Akar S 2007 ARIMA forecasting of primary energy demand by fuel in Turkey. Energy Policy 35: 1701-1708

[12] Ediger V Ş and Tatlıdil H 2002 Forecasting the primary energy demand in Turkey and analysis of cyclic patterns. Energy Convers. Manage. 43: 473-487

[13] Yumurtaci Z and Asmaz E 2004 Electric energy demand of Turkey for the year 2050. Energy Sources 26: 1157-1164

[14] Akkurt M, Demirel O F and Zaim S 2016 Forecasting Turkey's natural gas consumption by using time series methods. Eur. J. Econ. Polit. Stud. 3: 1-21

[15] Mucuk M and Uysal D 2009 Turkey's energy demand. Curr. Res. J. Soc. Sci. 1: 123-128

[16] Dilaver Z and Hunt L C 2011 Industrial electricity demand for Turkey: a structural time series analysis. Energy Econ. 33: $426-436$
[17] Sözen A and Arcaklioğlu E 2007 Prospects for future projections of the basic energy sources in Turkey. Energy Sources Part B 2: 183-201

[18] Kankal M, Akpınar A, Kömürcü M I and Özşahin T Ş 2011 Modeling and forecasting of Turkey's energy consumption using socio-economic and demographic variables. Appl. Energy 88: 1927-1939

[19] Sozen A, Arcaklioglu E and Ozkaymak M 2005 Modelling of Turkey's net energy consumption using artificial neural network. Int. J. Comput. Appl. Technol. 22: 130-136

[20] Ceylan H and Ozturk H K 2004 Estimating energy demand of Turkey based on economic indicators using genetic algorithm approach. Energy Convers. Manage. 45: 2525-2537

[21] Haldenbilen S and Ceylan H 2005 Genetic algorithm approach to estimate transport energy demand in Turkey. Energy Policy 33: 89-98

[22] Toksar1 M D 2007 Ant colony optimization approach to estimate energy demand of Turkey. Energy Policy 35: 3984-3990

[23] Kıran M S and Gündüz M 2013 A recombination-based hybridization of particle swarm optimization and artificial bee colony algorithm for continuous optimization problems. Appl. Soft Comput. 13: 2188-2203

[24] Uguz H and Hakli H 2015 A new algorithm based on artificial bee colony algorithm for energy demand forecasting in Turkey. In: Proceedings of the 4th International Conference on Advanced Computer Science Applications and Technologies (ACSAT), IEEE2015, pp. 56-61

[25] Kıran M S, Özceylan E, Gündüz M and Paksoy T 2012 Swarm intelligence approaches to estimate electricity energy demand in Turkey. Knowl.-Based Syst. 36: 93-103

[26] Ghanbari A, Kazemi S M R, Mehmanpazir F and Nakhostin M M 2013 A Cooperative Ant Colony Optimization-Genetic Algorithm approach for construction of energy demand forecasting knowledge-based expert systems. Knowl.-Based Syst. 39: 194-206

[27] Salcedo-Sanz S, Muñoz-Bulnes J, Portilla-Figueras J A and Del Ser J 2015 One-year-ahead energy demand estimation from macroeconomic variables using computational intelligence algorithms. Energy Convers. Manage. 99: 62-71

[28] Sánchez-Oro J, Duarte A and Salcedo-Sanz S 2016 Robust total energy demand estimation with a hybrid Variable Neighborhood Search - Extreme Learning Machine algorithm. Energy Convers. Manage. 123: 445-452

[29] Özdemir M 2013 Zaman Kısıtı Altında Takım Oryantiring Problemlerinin Yapay Arı Kolonisi Yaklaşımı ile Çözümü. İstanbul Üniversitesi Sosyal Bilimler Enstitüsü

[30] Qin A K, Huang V L and Suganthan P N 2009 Differential evolution algorithm with strategy adaptation for global numerical optimization. IEEE Trans. Evol. Comput. 13: 398-417

[31] Jędrzejowicz P and Skakovski A 2014 Island-based differential evolution algorithm for the discrete-continuous scheduling with continuous resource discretisation. Proc. Comput. Sci. 35: 111-117

[32] Liu Y, Rowe M, Holderbaum W and Potter B 2016 A novel battery network modelling using constraint differential evolution algorithm optimisation. Knowl.-Based Syst. 99: 10-18

[33] Mlakar U, Potočnik B and Brest J 2016 A hybrid differential evolution for optimal multilevel image thresholding. Expert Syst. Appl. 65: 221-232 
[34] Rogalsky T, Kocabiyik S and Derksen R 2000 Differential evolution in aerodynamic optimization. Can. Aeronaut. Space J. 46: 183-190

[35] Storn R 1996 On the usage of differential evolution for function optimization. In: Proceedings of the 1996 Biennial Conference of the North American Fuzzy Information Processing Society, NAFIPS, IEEE1996, pp. 519-523

[36] Parouha R P and Das K N 2016 A robust memory based hybrid differential evolution for continuous optimization problem. Knowl.-Based Syst. 103: 118-131

[37] Zorarpac1 E and Özel S A 2016 A hybrid approach of differential evolution and artificial bee colony for feature selection. Expert Syst. Appl. 62: 91-103

[38] Maciel L, Gomide F and Ballini R 2016 A differential evolution algorithm for yield curve estimation. Math. Comput. Simul. 129: 10-30

[39] Storn R and Price K 1997 Differential evolution-a simple and efficient heuristic for global optimization over continuous spaces. J. Glob. Optimizat. 11: 341-359

[40] Price K V 1999 An introduction to differential evolution. In: New ideas in optimization. Maidenhead, UK: McGrawHill

[41] Price K, Storn R M and Lampinen J A 2006 Differential evolution: a practical approach to global optimization. Springer Science \& Business Media

[42] Storn R and Price K 1995 Differential evolution-a simple and efficient adaptive scheme for global optimization over continuous spaces. Berkeley: ICSI
[43] Gämperle R, Müller S D and Koumoutsakos P 2002 A parameter study for differential evolution. Adv. Intell. Syst. Fuzzy Syst. Evol. Comput. 10: 293-298

[44] Karaboğa D 2014 Yapay Zeka Optimizasyon Algoritmalari

[45] Hrstka O and Kučerová A 2004 Improvements of real coded genetic algorithms based on differential operators preventing premature convergence. Adv. Eng. Softw. 35: 237-246

[46] Mayer D, Kinghorn B and Archer A 2005 Differential evolution - an easy and efficient evolutionary algorithm for model optimisation. Agric. Syst. 83: 315-328

[47] Özsağlam M Y and Cunkaş M 2008 Optimizasyon Problemlerinin Çözümü için Parçaçık Sürü Optimizasyonu Algoritmas1. Politek. Dergisi 11: 299-305

[48] Ronkkonen J, Kukkonen S and Price K V 2005 Real-parameter optimization with differential evolution. In: Proceedings of IEEE CEC2005, pp. 506-513

[49] Bulut Y M and Yildiz Z 2016 Comparing energy demand estimation using various statistical methods: the case of Turkey. Gazi Univ. J. Sci. 29: 237-244

[50] National Statistics (NS) 2016 http://www.tuik.gov.tr (in Turkish)

[51] Central Bank of Turkey (CBT) 2016 http://www.tcmb.gov.tr (in Turkish)

[52] TMMOB 2014 Elektrik enerjisi talep tahmin yöntemleri paneli (e-book, in Turkish)

[53] Geem Z W and Roper W E 2009 Energy demand estimation of South Korea using artificial neural network. Energy Policy 37: 4049-4054 